\title{
Avaliação do aprendizado discente: estudo com professores de Escolas Públicas
}

\section{Assessment of student learning: study with teachers of Public Schools}

\author{
Wagner Bandeira Andriola ${ }^{1}$
}

\begin{abstract}
RESUMO
O texto relata os resultados de um estudo efetivado com 40 professores do Sistema Educacional do Estado do Ceará, os quais foram sondados acerca das potencialidades e dificuldades inerentes à avaliação do aprendizado dos alunos. Os resultados da pesquisa sugerem que os professores: a) usam o diálogo com os alunos e os recursos audiovisuais como duas estratégias para motivá-los para o aprendizado; b) compreendem a aprendizagem como processo cognitivo de internalizar e aplicar os conhecimentos adquiridos; c) creem que são totalmente responsáveis pelo progresso dos discentes; d) dão ênfase à participação dos alunos nas atividades de sala de aula, ao desempenho destes em provas escritas, em pesquisas escolares e em trabalhos em grupo. Alegam, no entanto, que os principais empecilhos ao aprendizado são a falta de interesse dos alunos, a indisciplina em sala de aula, bem como o distanciamento da família da escola. De posse dos resultados das avaliações da aprendizagem, os professores geralmente revisam os conteúdos nos quais houve baixo nível de rendimento dos discentes, bem como tendem a refletir acerca dos erros mais cometidos pelos discentes. Com base nessas informações, alguns professores alegam modificar as estratégias de ensino, bem como usar estratégias pedagógicas mais variadas.

Palavras-chave: avaliação educacional; avaliação da aprendizagem; testes de rendimento.
\end{abstract}

${ }^{1}$ Doutor em Filosofia e Ciências da Educação (Universidad Complutense de Madrid); Coordenador de Avaliação Institucional da Universidade Federal do Ceará (UFC). Professor Associado do Departamento de Fundamentos da Educação, da Faculdade de Educação, da UFC; Membro da Associação Brasileira de Avaliação Educacional (ABAVE); Bolsista de Produtividade em Pesquisa (CNPq), Brasil. E-mail: w_andriola@ufc.br 


\begin{abstract}
This paper reports the results of a study with 40 teachers from the Educational System from the State of Ceará, which were probed on the potentialities and difficulties inherent in assessing student learning. The survey results suggest that teachers: a) use the dialogue with students and audiovisual resources as two strategies to motivate them for learning; b) understand the cognitive process of learning and how to internalize and apply the acquired knowledge, c) believe they are fully responsible for the progress of students; d) give emphasis to the students' participation in the classroom activities as well as to their performance in a written exam, in school research and in group works. They argue, however, that the main obstacles to their learning are lack of students' interest, lack of discipline in the classroom and the distance between the family and the school. With the results of learning assessment, teachers often review the contents of which students had low performance, and they tend to reflect more about the errors committed by students. Based on this information some teachers claim to modify teaching strategies and use more varied teaching strategies.
\end{abstract}

Keywords: educational assessment; learning assessment; achievement tests.

\title{
Avaliação do aprendizado: alguns dados interessantes
}

No artigo "A batalha pela qualidade", publicado pela revista Veja (n. 27, de 9 de julho de 2003), há amplo espaço destinado à apresentação dos resultados da avaliação do aprendizado de alunos de 15 anos, executada pela Organização para a Cooperação e o Desenvolvimento Econômico (OCDE), nas áreas de matemática, ciências e leitura. Dentre 41 países avaliados, o Brasil ocupou o $37^{\circ}$ posto em leitura; em matemática e ciências obtivemos um vergonhoso penúltimo lugar. O que indicam esses dados? Pois que, dentre muitas dificuldades do nosso sistema educacional, existem deficiências estruturais na educação fundamental, cujos reflexos mais visíveis são os fracos desempenhos dos discentes em sistemáticas avaliativas. Ademais, a partir dos mencionados resultados, pode-se inferir que a atuação docente é, em geral, inadequada; que os currículos necessitam de atualizações; que os alunos estão desmotivados; que há condições paupérrimas para o ensino e, por conseguinte, para que se dê o adequado aprendizado discente (ANDRIOLA, 2011).

Os resultados obtidos no Programa Internacional de Avaliação de Alunos (PISA), realizado em 2009, apontaram que os aprendizes do Distrito Federal 
foram os que atingiram a melhor pontuação entre os 20.000 brasileiros que participaram, com valor médio de 439 pontos, 38 pontos acima da média nacional. Em seguida, apareceram os alunos de Santa Catarina (média de 428 pontos), Rio Grande do Sul (média de 424 pontos), Minas Gerais (média de 422 pontos) e Paraná (média de 417 pontos). Seis Estados também tiveram resultados acima da média nacional: Espírito Santo, São Paulo, Rio de Janeiro, Mato Grosso do Sul e Goiás. Em 2009, o Brasil aumentou o plano amostral e o número de alunos participantes para que os resultados do PISA pudessem ser comparados por Estado.

Os alunos com os piores desempenhos foram os de Alagoas (média de 354 pontos) e do Maranhão (média de 355 pontos), vindo, na sequência, o Acre, o Amazonas e o Rio Grande do Norte, cujas médias obtiveram valores de 371 pontos. Parece ser que os resultados inferiores dos Estados do Norte e do Nordeste são reflexos do baixo investimento educacional que foi feito nessas regiões, nos últimos anos.

Centrando-nos especificamente em valorar a qualidade dos resultados a partir do desempenho dos discentes, podemos afirmar que, no caso da área de matemática, os aprendizes brasileiros dominam tão somente as quatro operações básicas - apresentam desempenho insatisfatório em operações mais complexas, na identificação de formas geométricas e no entendimento dos enunciados dos problemas. A prova de leitura revela que os aprendizes brasileiros conseguem ler, mas são incapazes de reter e de interpretar as frases, demonstrando, assim, pobreza vocabular.

Com esses dados, os responsáveis pelas políticas públicas educacionais podem reorientar suas ações e elaborar planejamentos visando solucionar ou minimizar tão graves deficiências. Nesse ponto reside a função maior da avaliação: conhecer uma realidade para julgá-la e, posteriormente, aprimorá-la (HARLEN, 2006).

Países comprometidos com a implementação de políticas educacionais que democratizem o acesso à Educação dos segmentos sociais menos favorecidos focalizam, prioritariamente, a avaliação do grau de aprendizado alcançado pelos alunos, isto é, o grau de consecução dos objetivos escolares, como um dos mais relevantes indicadores da qualidade do sistema educacional (DE ARUANI; MAGIONI, 2006).

No contexto brasileiro, a Lei de Diretrizes e Bases da Educação (LDB $n^{\circ}$ 9.394, de dezembro de 1996) proporciona base legal para a avaliação do aprendizado, visto que menciona no Artigo 24, Seção I, Capítulo II: 
A verificação do rendimento escolar observará os seguintes critérios:

a) avaliação contínua e cumulativa do desempenho do aluno, com prevalência dos aspectos qualitativos sobre os quantitativos e dos resultados ao longo do período sobre os de eventuais provas finais;

b) possibilidade de aceleração de estudos para alunos com atraso escolar;

b) possibilidade de avanço nos cursos e nas séries mediante verificação do aprendizado;

d) aproveitamento de estudos concluídos com êxito;

e) obrigatoriedade de estudos de recuperação, de preferência paralelos ao período letivo, para os casos de baixo rendimento escolar, a serem disciplinados pelas instituições de ensino em seus regimentos. (BRASIL, 1996).

Como podemos observar, na alínea $a$, há ênfase na avaliação contínua e cumulativa do desempenho do aluno. Parece óbvia a necessidade de contarmos com informações válidas sobre o progresso dos aprendizes. Sendo assim, devemos avaliá-los sistematicamente. Não obstante, devemos mencionar a existência de várias estratégias ou procedimentos, que poderão ser utilizados no processo avaliativo:

- Observações em sala de aula para verificar como o aluno interage, como se comporta, sua frequência diária, seu compromisso com as tarefas de casa, dentre outros;

- Questionários para identificar o que opinam os discentes acerca das aulas, dos conteúdos, do professor, da escola, dos amigos;

- Seminários - como o aprendiz usa a capacidade de expressão verbal, de cooperação, de organização coletiva etc.;

- Provas de rendimento para apreender como o estudante usa as capacidades cognitivas que compõem a aprendizagem;

- Atividades extracurriculares para identificar a execução de procedimentos, tais como: pesquisas em bibliotecas, jornais, livros etc.

É bom que se diga que essa lista de procedimentos não tem a pretensão de ser exaustiva, ilustra, tão somente, a amplitude de possibilidades que os docentes possuem para avaliar a aprendizagem dos seus pupilos (JAMES, 2006; KOLLER, 2006).

Com respeito ao segundo aspecto, que se refere à possibilidade de aceleração de estudos para alunos com atraso escolar, merece alguma reflexão. Estamos ressaltando que a avaliação do aprendizado implica, necessariamente, observar o grau de consecução dos objetivos curriculares. Acelerar alunos com atraso escolar significa proporcionar o acesso, a um nível de ensino mais complexo, de um aprendiz que não alcançou os objetivos curriculares propostos 
para o seu nível e que, portanto, não possui, ainda, as capacidades cognitivas que lhe serão exigidas nesse novo âmbito. Portanto, usando uma terminologia popular, esse tipo de procedimento implica "tapar o sol com a peneira". Opinamos que é um engodo, uma estratégia para mascarar o fracasso de algumas políticas educacionais.

$\mathrm{Na}$ alínea $c$, ressalta-se que haverá avanço nos cursos e nas séries mediante verificação do aprendizado. Esse é um aspecto bastante claro: só poderá seguir adiante aquele aprendiz que demonstrar haver alcançado os objetivos curriculares propostos para o seu nível cognitivo. Como ressaltamos anteriormente, há inúmeros procedimentos para avaliar o aprendizado do aluno, cabendo ao docente conhecê-los e aplicá-los de modo adequado.

Finalmente, a alínea $e$ dispõe sobre a obrigatoriedade de estudos de recuperação, de preferência paralelos ao período letivo, para os casos de baixo rendimento escolar. Essa ideia vai de encontro, afortunadamente, ao estabelecido no item $b$, que trata da aceleração dos estudos, ao qual nos posicionamos contra. Cabe ao docente, tendo observado que seu aprendiz não acompanha o progresso dos demais companheiros, adotar outros procedimentos, paralelos aos de sala de aula, com o nobre objetivo de proporcionar-lhe condições de alcançar os objetivos curriculares propostos ao início do curso. Essa é uma medida sensata que não tenta mascarar a realidade educacional, muitas vezes dura, mas, isso sim, propõe estratégias alternativas com o claro intuito de minimizar o fracasso ou o insucesso escolar.

Nessa altura temos que nos indagar acerca do que estamos compreendendo acerca do aprendizado. Para tal, haveremos que conhecer as várias visões e definições do que seja aprendizagem.

\section{Concepções teóricas de aprendizado}

As concepções de aprendizado têm sofrido muitas e radicais modificações, durante o curto período de existência da Ciência Psicológica. Puentes Ferreras (1998) e Andriola (2004) realizam excelentes sínteses da evolução do conceito de aprendizagem, considerando o progresso teórico das posições comportamentista e cognitivista, passando pela neocognitivista. De acordo com Puentes Ferreras (1998), é possível organizar essa evolução de concepções em três grupos distintos:

- I-Aprendizagem como aquisição de respostas: expressa a concepção da ampla maioria dos autores da corrente comportamentista. Está pre- 
sente desde o condicionamento clássico de Ivan P. Pavlov, passando pelo instrumental de Edward L. Thorndike, até o condicionamento operante de Burhus F. Skinner, que recebe influências das anteriores e advoga por um caráter determinista do comportamento, condicionado pelas consequências derivadas do mesmo. Trata-se de uma ideia de aprendizagem associacionista, mecânica e determinada. Nesta perspectiva, o aluno é um sujeito passivo e o professor um conhecedor de estímulos - eliciadores, reforçadores, discriminativos, primários, secundários, generalizados, contínuos e intermitentes - e reforços positivos, negativos e aversivos - que devem ser utilizados para a consecução de uma resposta de tipo instrumental, observável publicamente, através de recompensa, castigo, esquiva etc. O processo de ensino-aprendizagem fica reduzido a uma concepção mentalista, que defende: (i) uma aprendizagem composta de conexões entre estímulos e respostas, que teriam lugar na mente; (ii) uma concepção instrumental, na medida em que o aluno aprende um comportamento que é um instrumento para alcançar uma recompensa; (iii) uma concepção ambientalista, na qual a conduta é diretamente observável e controlável através de programas de estímulos e reforços (RAMOS, 1999). Nos três casos se elimina, portanto, o efeito da interação professor-conteúdo-aluno, próprio de uma situação de ensino-aprendizagem;

- II - Aprendizagem como aquisição de conhecimentos: tem como marco inicial as investigações sobre a aprendizagem animal, próprias da corrente comportamentista, desembocando nas investigações sobre mapas cognitivos com sujeitos humanos (STERNBERG; GRIGORENKO, 2003). Centra-se no estudo dos processos mentais, isto é, nos mecanismos internos que estão subjacentes ao comportamento humano, dando pouca importância aos elementos externos ao organismo. Nesse período, surge a clássica metáfora "mente-computador", bem como o interesse por estudar a chamada "caixa-negra", que durante tanto tempo os comportamentistas haviam deixado em segundo plano, frente à relevância dada aos inputs e outputs - elementos internos e externos ao organismo. Desde essa perspectiva, a aprendizagem e o comportamento surgem de uma interação com o ambiente, não como resultado ou resposta a simples estímulos, senão como conexões entre estruturas mentais chamadas esquemas. A realidade cognitiva do organismo é posta em evidência, isto é, o sujeito adquire conhecimentos, armazena e processa informação, todavia não tem controle sobre o seu processo de aprendizagem. O professor é um transmissor de conhecimentos. Em definitivo, o processo de ensino-aprendizagem se centra 
no processamento de informação (RAMOS, 1999; POZO, 2002);

- III - Aprendizagem como construção de significados: coincide com o período de maturidade da psicologia cognitiva, cujos frutos são coletados atualmente. Entre as suas diversas subáreas encontram-se algumas conhecidas, tais como: o construtivismo, a significação e a modificação cognitiva. Os investigadores dessas novas áreas supõem o aprendiz como um sujeito ativo, autônomo, que pouco a pouco pode conhecer os seus próprios processos cognitivos - estilos de aprendizagem (LINS, 2000; MISHNE, 1999). O aluno já não se limita a adquirir conhecimentos, senão que os constrói usando a experiência para compreender e modelar o novo. O professor não apresenta conhecimentos, senão procedimentos-chave para que o próprio sujeito possa construir sua aprendizagem (ANDRIOLA, 2004). A palavra-chave dessa última vertente teórica é aprender a aprender.

A evolução das concepções de aprendizagem possibilitou a formulação de uma definição bastante conhecida pelos psicólogos e teóricos da área, que é apresentada por Howe (1999). Trata-se de uma definição eminentemente cognitivista:

Es útil considerar el aprendizaje como un término amplio, que se refiere no sólo a una única actividad, sino a toda una familia de procesos y de hechos mentales que, de una u otra manera, permiten incrementar el conocimiento o aumentar las habilidades y capacidades cognitivas (Howe, 1999, p. 22).

Existem, segundo Howe (1999), três princípios que fundamentam o processo de aprendizado:

- I - Processamento mental ativo: afirma que o aprendiz deve ter um papel relevante no processo de ensino-aprendizado. Deve ser um sujeito ativo, já que a eficácia do processo pode ser muito maior se os aprendizes estão envolvidos com as tarefas ou atividades pedagógicas, isto é, se estão motivados a aprender;

- II - Estabelecimento de relações significativas: é caracterizado pelo estabelecimento de vínculos entre os elementos aprendidos recentemente; pelo estabelecimento de relações entre o material aprendido recentemente e as informações que o aprendiz já conhecia de antemão. Tais características supõem a adoção de um papel ativo por parte do aprendiz, isto é, o sujeito é o principal responsável pela associação 
entre os conteúdos aprendidos, através da execução de inúmeros procedimentos: novas leituras, consultas bibliográficas, análise e síntese, revisão sistemática do conteúdo etc.;

- III - Repetição sistemática: destacamos a revisão de conteúdos - cujos componentes são majoritariamente cognitivos, p. ex., aprendizado da matemática - e a repetição de uma prática - cujos componentes são majoritariamente físicos, p. ex., aprendizado da natação e da música. Sabemos que em muitas ocasiões haverá uma mistura de ambos os tipos - p. ex., aprendizado do xadrez.

Esses três princípios podem ser perfeitamente potencializados no ambiente escolar. Com efeito, talvez seja esse o maior desafio dos professores: organizar o conteúdo didático de modo que os seus alunos incrementem esses três aspectos, conforme opinam Anderson (1995) e Howe (1985).

Todavia, é necessário aclarar mais alguns aspectos subjacentes à aprendizagem. Por exemplo, está claro que a aprendizagem constitui processo pelo qual o comportamento de um organismo sofre mudanças, embora nem toda mudança resulte da aprendizagem (BIAGGIO, 1991). É preciso distinguir muito cuidadosamente entre mudanças que são consequências diretas da aprendizagem e aquelas que não têm nenhuma relação com a mesma. Por exemplo, a fadiga pode alterar o comportamento, mas as mudanças resultantes não se devem à aprendizagem. De forma parecida, as mudanças produzidas pela maturação não devem ser classificadas como aprendidas ou adquiridas. Uma criança cresce até que, finalmente, alcança o interruptor da lâmpada e consegue acendê-la. Como destaca Biaggio (1991), a maturação física - aumento de estatura - está, em grande medida, implicada nesta mudança de comportamento, ainda que possa intervir na aprendizagem.

Um problema com o qual se deparam os investigadores dessa área reside em responder a uma indagação que, em um primeiro momento, pode ser irrelevante para muitos: é possível avaliar o aprendizado de modo consistente? Esta temática será abordada agora.

\section{Avaliação do aprendizado}

No âmbito das correntes cognitivistas, o aprendizado pode ser considerado mudança qualitativa e estável, ocorrida nos processos mentais de memorização, compreensão, aplicação, análise, síntese e julgamento, dentre outras (ANDRIOLA, 2004). Esse câmbio comportamental pode ser avaliado através de inúmeros 
procedimentos, todos eles apropriados ao fim de averiguar o progresso discente. Alguns desses procedimentos são exemplificados através do uso sistemático de: testes ou provas de rendimento; questionários; seminários; observações em sala de aula; frequência de participação durante as aulas; execução de tarefas extra-sala de aula etc. (SAAVEDRA, 2008).

Cabe destacar, ainda, que as capacidades cognitivas características da aprendizagem estão associadas a determinados conteúdos ou objetivos curriculares (PÉREZ GÓMEZ, 2009). Assim, por exemplo, o professor de português, através do uso de um texto literário qualquer, poderá medir o grau de consecução de objetivos curriculares, tais como:

- Ser capaz de compreender um texto literário - exige-se a capacidade cognitiva de compreensão;

- Ser capaz de analisar os elementos explícitos de uma mensagem exige-se a capacidade cognitiva de análise;

- Ser capaz de sintetizar uma mensagem original em uma segunda forma paralela e mais simples - exige-se a capacidade cognitiva de sintese;

- Ser capaz de julgar o valor literário de uma obra, com base em critérios preestabelecidos - exige-se a capacidade cognitiva de julgamento.

No mencionado exemplo, o professor estará avaliando o grau no qual os seus aprendizes alcançaram quatro objetivos educativos ou curriculares associados às mais distintas capacidades cognitivas, todas elas componentes da aprendizagem.

Nesse âmbito, faz-se necessário recordar o propósito de toda e qualquer sistemática avaliativa: fornecer subsídios para que os responsáveis pela coordenação e planejamento de ações educativas possam tomar decisões, visando ao seu aperfeiçoamento (ANDRIOLA, 2004). No caso da sala de aula, caberá ao professor avaliar os seus alunos para que, assim, possa julgar a adequação da sua atuação docente e o progresso individual dos aprendizes. Baseado nessas informações, poderá o docente rever os procedimentos pedagógicos utilizados $\mathrm{e}$, ademais, orientar os alunos que não alcançaram os objetivos educacionais, planejados a priori.

Os fins educativos consistem, essencialmente, em determinar as mudanças que sofrem os aprendizes, isto é, as transformações nas formas de comportamento dos estudantes quanto à aquisição de novas aprendizagens. Sendo assim, a avaliação da aprendizagem é o processo pelo qual se pode determinar em que medida ou grau tais mudanças ocorreram, possibilitando, assim, juizo de valor acerca da qualidade dessas supostas mudanças. Nesta definição existem duas ideias básicas:

- I - O objeto da avaliação é o comportamento: o comportamento é entendido como sendo determinado por atributos intrapsíquicos 
ou orgânicos - tais como a motivação, compreensão, raciocínio, memorização, entre outros, que são base da aprendizagem -, pelos quais a tarefa avaliadora consiste na busca das manifestações externas que sirvam de indicadores válidos acerca dos aspectos internos, não avaliados diretamente. As relações entre os atributos internos e as manifestações externas - p. ex.: as respostas aos itens de um teste de rendimento - têm por base modelos psicométricos, tais como a Teoria Clássica dos Testes (TCT) ou a moderna Teoria de Resposta ao Item (TRI). Os objetivos pretendidos são a descrição e a posterior predição do comportamento a partir dos resultados obtidos em um ou mais testes de rendimento;

- II - A avaliação deve ser um processo sistemático de coleta e análise de informações: deve proporcionar pelo menos duas medidas: uma no início do processo de ensino e outra no final, posto que sua finalidade última é a valoração da qualidade das mudanças comportamentais devidas à aprendizagem. É interessante dizer que todo testemunho conversas informais, debates em sala de aula, participação dos alunos etc. - é válido para avaliar a aprendizagem. Os testes de rendimento são uma dessas inumeráveis formas de dar testemunhos, pois permitem a obtenção de informações úteis, válidas e fidedignas sobre o progresso dos estudantes. Não obstante, em qualquer testemunho existem duas etapas que devem ser seguidas:

a) seleção de comportamentos ou ações que sejam indicadores dos objetivos curriculares que se deseja avaliar;

b) apresentação de tarefas pedagógicas que possibilitem aos alunos expressar o que sabem acerca do conteúdo avaliado.

Nesse contexto, é possível dizer que os testes de rendimento compõem o grupo de procedimentos científicos para obter observações sistemáticas, em situações estruturadas ou tipificadas, com a finalidade de descrever o comportamento do aprendiz (TYLER, 1981). Devemos destacar, nesse ponto, que, durante a aplicação dos testes de rendimento, a padronização das condições é fundamental, isto é, instruções, tempo de aplicação ou qualquer outra condição devem ser similares. A possibilidade de comparar o mesmo sujeito em diferentes testes ou diferentes alunos no mesmo teste se baseia, precisamente, em manter as mesmas condições de aplicação.

Com base no que foi exposto, planejou-se a execução de uma investigação científica direcionada aos docentes de escolas públicas do município de Fortaleza, com os objetivos de:

a) identificar as principais estratégias e posturas adotadas pelos docentes com o intuito de motivar os discentes; 
b) identificar a concepção de aprendizagem discente e o papel do professor no processo de ensino e aprendizado;

c) identificar os principais procedimentos utilizados pelo docente para avaliar o aprendizado discente;

d) identificar o uso que o docente faz dos resultados da avaliação do aprendizado discente;

e) identificar as principais dificuldades encontradas pelos docentes no processo de ensino e aprendizado e os meios utilizados para superá-las;

f) identificar as principais dificuldades enfrentadas pela instituição educacional;

g) identificar o grau de participação da família no processo de ensino e de aprendizado discente.

\section{Método utilizado na investigação}

Foi efetivado estudo de campo do tipo ex post-facto com 40 docentes de instituições educacionais de natureza pública do município de Fortaleza (Ceará), que foram escolhidas de acordo com os seguintes critérios de conveniência: facilidade de deslocamento dos bolsistas à instituição educacional; aceite da direção da instituição educacional em participar da investigação e, por fim, facilidade em abordar os docentes.

\section{Procedimento de coleta de dados}

Após treinamento, dois bolsistas de Iniciação Científica (IC) ${ }^{2}$ do Conselho Nacional de Desenvolvimento Científico e Tecnológico (CNPq), ambos do Curso de Pedagogia (noturno) da Faculdade de Educação (FACED) da Universidade Federal do Ceará (UFC), dirigiram-se às escolas contatadas a priori para procederem à coleta das informações, por meio do emprego de um questionário semiaberto. $\mathrm{O}$ referido instrumento foi aplicado individualmente aos docentes partícipes, sem haver limitação de tempo para o preenchimento.

${ }^{2}$ Agradecemos aos discentes do curso de Pedagogia da UFC, Aécliton da Silva Forte e Laécio Nobre de Macedo, pelo envolvimento e correção demonstrados durante todo o decorrer da pesquisa. 


\section{Instrumento de coleta de dados}

Utilizou-se questionário semiaberto contendo 21 questões, sendo nove destinadas à identificação sociodemográfica dos respondentes e as demais versando sobre as principais estratégias e posturas para motivar os discentes; a concepção de aprendizagem discente e o papel do professor nesse processo; os principais procedimentos utilizados para avaliar o aprendizado discente; o uso que se faz dos resultados da avaliação do aprendizado discente; as principais dificuldades encontradas no processo de ensino e aprendizado e os meios utilizados para superá-las; as principais dificuldades enfrentadas pela instituição educacional e, por fim, o grau de participação da família no processo de ensino e aprendizado discente.

\section{Descrição da amostra docente}

Foram sondados 40 docentes, sendo a maioria do gênero feminino $(\mathrm{n}=$ 34 ou $85 \%$ ), cujo estado civil era casado $(\mathrm{n}=26$ ou $65 \%$ ) e com idade modal variando entre 31 e 35 anos ( $\mathrm{n}=14$ ou $35 \%)$. Quanto à formação, 62,5\% são Pedagogos $(n=25)$, sendo que $30 \%$ do total $(n=12)$ obtiveram o título na Universidade Vale do Acaraú (UVA), com 62,5\% $(n=25)$ tendo entre um e dez anos de atuação docente. Os referidos profissionais estavam atuando na época da coleta dos dados na Educação Infantil ( $\mathrm{n}=10$ ou $25 \%$ ), no Ensino Fundamental $(\mathrm{n}=23$ ou $57,5 \%)$ e Médio $(\mathrm{n}=7$ ou $17,5 \%)$.

\section{Apresentação e discussão dos resultados}

Cumpre destacar, inicialmente, que as informações brindadas pelos docentes foram tratadas qualitativamente, através do emprego da técnica de análise de conteúdo (BARDIN, 1977), cujo objetivo foi identificar as categorias de resposta mais relevantes aos propósitos da investigação e que, ademais, fossem pertinentes às indagações feitas. Posteriormente, foram calculados os percentuais de aparição das categorias identificadas, conforme as descrições a seguir realizadas. 
Primeiramente, no que tange à adoção de estratégias pedagógicas e das posturas para motivar os discentes, foram identificadas como sendo as principais:

- Emprego do diálogo com os discentes, mencionado por $35 \%$ dos docentes $(\mathrm{n}=14)$;

- Utilização de dinâmicas de grupo, referida por $27,5 \%$ dos sujeitos $(\mathrm{n}=11)$;

- Uso de recursos audiovisuais e de informática, destacado por $25 \%$ dos entrevistados $(\mathrm{n}=10)$.

Acerca das concepções que os docentes possuem do aprendizado discente, os seguintes dados foram obtidos:

- Aprender significa internalizar conhecimentos, que foi citado por $45 \%(\mathrm{n}=18)$;

- Aprender significa adquirir e aplicar conhecimentos, que foi mencionado por $35 \%(\mathrm{n}=14)$;

- Aprender é sinônimo de mudança comportamental, que foi citado por $20 \%(n=8)$.

Indagados acerca do papel do professor no processo de aprendizado dos discentes, a maior parte dos entrevistados $(50 \%$ ou $\mathrm{n}=20)$ crê que referido agente educacional é totalmente responsável pelo progresso dos discentes, enquanto outros $45 \%(\mathrm{n}=18)$ asseveram que a responsabilidade pode ser parcialmente atribuída ao docente. Tão somente $5 \%$ dos entrevistados $(\mathrm{n}=2)$ asseveraram acreditar que inexiste responsabilidade do docente para com o aprendizado dos discentes.

No que diz respeito aos procedimentos utilizados para avaliar $\mathrm{o}$ aprendizado dos discentes, ${ }^{3}$ foram identificados os seguintes:

- Participação nas atividades de sala de aula, que foi referida em $41 \%$ das respostas $(\mathrm{n}=34)$;

- Prova escrita, que foi destacada em 19,3\% das respostas ( $\mathrm{n}=16)$;

- Pesquisa ou trabalhos em grupo, que foram citados em 19,3\% das respostas $(\mathrm{n}=16)$;

- $\quad$ Seminário, que foi mencionado em $13,2 \%$ das respostas $(\mathrm{n}=11)$;

- Autoavaliação discente, que foi identificado em aproximadamente $5 \%$ das respostas $(\mathrm{n}=4)$.

${ }^{3}$ Cada docente mencionou mais de um procedimento para avaliar o aprendizado dos discentes, resultando, por isso mesmo, um total de respostas $(n=50)$ superior ao tamanho da amostra estudada $(n=40)$. 
Quanto ao uso das informações resultantes da avaliação do aprendizado discente, os docentes destacaram várias possibilidades que foram agrupadas nas seguintes categorias:

- Revisar os conteúdos nos quais houve baixo nível de rendimento dos discentes, que foi referido por $37,5 \%$ dos docentes $(\mathrm{n}=15)$;

- Refletir acerca dos erros mais cometidos pelos discentes, que foi mencionado por $35 \%$ dos docentes $(\mathrm{n}=14)$;

- Modificar as estratégias de ensino, que foi citada por 22,5\% dos docentes $(\mathrm{n}=9)$;

- Conversar com os pais dos alunos, que foi mencionada por tão somente $5 \%$ dos docentes $(n=2)$.

No que diz respeito às principais dificuldades presentes no processo de ensino e aprendizado,${ }^{4}$ foram identificadas as seguintes:

- $\quad$ Falta de interesse dos discentes, que foi citada em $24,7 \%$ das respostas $(\mathrm{n}=19)$;

- Indisciplina dos discentes, que foi referida em $22,1 \%$ das respostas $(\mathrm{n}=17)$;

- Falta de acompanhamento familiar, que foi mencionada em $20,8 \%$ das respostas $(\mathrm{n}=16)$;

- Material didático inadequado às características dos discentes, que foi citada em 10,4\% das respostas $(n=8)$.

Os docentes mencionaram como sendo os principais meios utilizados para superar as dificuldades presentes no processo de ensino e aprendizado: ${ }^{5}$

- Usar estratégias pedagógicas variadas, que esteve presente em $36 \%$ das respostas $(\mathrm{n}=18)$;

- Manter diálogo franco com os discentes, que foi mencionado em $28 \%$ das respostas $(\mathrm{n}=14)$;

- Buscar diálogo com os pais ou os responsáveis pelos discentes, que foi identificada em $16 \%$ das respostas $(\mathrm{n}=8)$.

No que concerne às principais dificuldades enfrentadas pela instituição educacional, os docentes mencionaram as seguintes: ${ }^{6}$

${ }^{4}$ Também aqui cada docente mencionou mais de uma dificuldade presente no processo de ensino e aprendizado, resultando, por isso mesmo, um total de respostas $(n=77)$ superior ao tamanho da amostra estudada $(n=40)$.

${ }^{5}$ Igualmente como ocorrido anteriormente, também aqui cada docente mencionou mais de um procedimento para superar as dificuldades presentes no processo de ensino e aprendizado, resultando, por isso mesmo, um total de respostas $(\mathrm{n}=50)$ superior ao tamanho da amostra estudada $(\mathrm{n}=40)$.

${ }^{6}$ Como ocorrido em situações anteriores, também aqui cada docente mencionou mais de um procedimento para superar as dificuldades presentes no processo de ensino e aprendizado, resultando, por isso mesmo, num total de respostas $(n=41)$ superior ao tamanho da amostra estudada $(n=40)$. 
- Falta de material didático, que foi sugerida em 39\% das respostas $(\mathrm{n}=16)$;

- Inadequação dos espaços destinados à convivência/recreação, que foi mencionado em $24 \%$ das respostas $(\mathrm{n}=10)$;

- Inadequação das salas de aula, que foi enumerado em $22 \%$ das respostas $(\mathrm{n}=9)$.

Finalmente, quanto à participação da família no processo de ensino e de aprendizado discente, constatou-se baixo grau de envolvimento familiar, conforme destacado por $65 \%$ das respostas dos professores $(n=26)$.

\section{Síntese valorativa dos dados}

Os resultados da pesquisa sugerem que os professores usam o diálogo com os alunos e os recursos audiovisuais como duas estratégias para motivá-los para o aprendizado. Os professores compreendem a aprendizagem como processo cognitivo de internalizar e aplicar os conhecimentos adquiridos no processo de ensino. O papel dos professores nesse processo é de agente totalmente responsável pelo progresso dos discentes, apesar de um grupo menor de professores ter asseverado que a responsabilidade pode ser parcialmente atribuida aos docentes. Os professores dão ênfase à participação dos alunos nas atividades de sala de aula, ao desempenho destes em provas escritas, em pesquisas escolares e em trabalhos em grupo.

Alegam, no entanto, que os principais empecilhos ao aprendizado são a falta de interesse dos alunos, a indisciplina em sala de aula, bem como o distanciamento da família da escola. De posse dos resultados das avaliações da aprendizagem, os professores geralmente revisam os conteúdos nos quais houve baixo nivel de rendimento dos discentes, bem como tendem a refletir acerca dos erros mais cometidos pelos discentes. Com base nessas informações, alguns professores alegam modificar as estratégias de ensino, bem como usar estratégias pedagógicas mais variadas. Apesar desse esforço para modificar a atuação docente e a didática empregada em sala de aula, os professores apontam dificuldades, tais como: falta de material didático, inadequação das salas de aula e baixo grau de envolvimento familiar. 


\section{À guisa de conclusão}

Destacamos que à avaliação da aprendizagem lhe cabe a função de delimitar as aquisições e os modos de raciocínio de cada aprendiz, de maneira que o professor possa auxiliá-lo a progredir e, assim, alcançar ou aproximar-se, o máximo possível, dos objetivos curriculares propostos a priori. Nesse âmbito, a avaliação, torna-se uma atividade necessária e imprescindivel, porque é uma estratégia pedagógica de luta contra of fracasso escolar e, por conseguinte, das desigualdades sociais.

O problema é que os resultados pífios dos nossos estudantes em sistemática avaliativa de natureza internacional revelam o descaso da educação em nosso país. De fato, conforme revelaram os professores partícipes da pesquisa, a falta de interesse do alunado, a indisciplina em sala de aula e o distanciamento da família do ambiente escolar são fatores intimamente associados ao baixo desempenho dos alunos nas avaliações do aprendizado. Aliem-se a estes problemas a falta de material didático e a inadequação das salas de aula e teremos um cenário muito propício aos aprendizados muito superficiais.

O relatório do PISA de 2009 assevera que os sistemas educacionais considerados de sucesso gastam muito dinheiro em educação e tendem a priorizar o salário docente à formação de classes de alunos menores. De acordo com a pesquisa, o melhor desempenho dos estudantes está relacionado aos salários mais altos dos professores e não a turmas com menos alunos. Para a OCDE, os sistemas que fazem isso comprovam pesquisas que afirmam que aumentar a qualidade do professor é uma rota mais efetiva para melhorar os resultados dos estudantes do que criar turmas menores.

Dentro dos países, afirma o relatório do PISA, escolas com melhores recursos geralmente têm desempenho melhor por tenderem a ter mais estudantes "socioeconomicamente favorecidos". Alguns locais, diz a pesquisa, têm grande relação entre os recursos e o ambiente demográfico e socioeconômico da região onde as escolas se encontram. "Se a maioria ou todas as escolas tiverem o mínimo de recursos necessários para permitir um ensino efetivo, recursos materiais adicionais podem fazer mínima diferença nos resultados", diz o relatório. ${ }^{7}$ Portanto, está demonstrado o que somente os nossos governantes não veem: investir em educação proporciona os melhores resultados para uma nação (Benjamin Franklin).

7 Ver o site <http://www.oecd.org/document/61/0,3746,en_32252351_46584327_ 46567613_1_1_1_1,00.html>. Acesso em: 23/04/2011. 


\section{REFERÊNCIAS}

ANDERSON, J. R. Cognitive psychology and its implications. New York: Freeman, 1995. ANDRIOLA, W. B. Avaliação da aprendizagem: conceitos, dados, problemas e perspectivas. Psicologia Argumento, Curitiba, v. 22, n. 39, p. 45-55, 2004.

. Avaliação da aprendizagem de alunos: análise panorâmica acerca de conceitos e procedimentos metodológicos. In: VASCONCELOS, J. G.; SANTANA, J. R. O pensamento pedagógico hoje. Fortaleza: Edições UFC, 2011. p. 198-227.

BARDIN, L. Análise de conteúdo. Lisboa, Portugal: Edições 70, 1977.

BIAGgiO, A. M. B. Psicologia do desenvolvimento. Petrópolis: Vozes, 1991.

BRASIL. Ministério da Educação e Cultura. LDB - Lei n. 9.394/96, de 20 de dezembro de 1996. Estabelece as diretrizes e bases da Educação Nacional. Brasília: MEC, 1996.

DE ARUANI, M. B.; MAGIONI, B. E. Evaluación de los aprendizajes. Buenos Aires: Ediciones Novedades Educativas, 2006.

HARLEN, W. On the relationship between assessment for formative and summative purposes. In: GARDNER, J. (Ed.). Assessment and Learning. London: Sage, 2006. p. 103-118.

HOWE, M. J.A. A teacher's guide to the psychology of learning. Oxford: Blackwell, 1985.

. La capacidad de aprender. La adquisición y desarrollo de habilidades. Madrid: Alianza Editorial, 1999.

JAMES, M. Assessment, teaching and theories of learning. In: GARDNER, J. (Ed.). Assessment and Learning. London: Sage, 2006. p. 47-60.

KOLLER, O. Formative assessment in classrooms: A review of the empirical German literature. In: OECD (Ed.). Formative Assessment: Improving Learning in Secondary Schools. Paris: OECD Publishing, 2006. p. 265-275.

LINS, S. D. O modelo cognitivista de ensino-aprendizagem. Cadernos de Educação, Fortaleza, v. 24, p. 46-56, 2000.

MISHNE, J. M. A curva da aprendizagem. Elevando a competência acadêmica e social. Porto Alegre: Artmed, 1999.

PÉREZ GÓMEZ, A. La evaluación como aprendizaje. Madrid: Ediciones AKAL, 2009. PÉREZ JUSTE, A.; GARCÍA RAMOS, R. Diagnóstico, evaluación y tomada de decisiones. Madrid: Ediciones Rialp, 1989.

POZO, J. I. Teorias cognitivas de aprendizagem. Porto Alegre: Artmed, 2002. 
PUENTES FERRERAS, A. Cognición y aprendizaje. Fundamentos psicológicos. Madrid: Ediciones Psicología Pirámide, 1998.

RAMOS, E. A. Aprendizagem humana. Cadernos de Educação, Fortaleza, v. 23, p. 37-49, 1999.

SAAVEDRA, M. Evaluación del aprendizaje: conceptos y técnicas. México: Editorial Pax, 2008.

STERNBERG, R. J.; GRIGORENKO, E. L. Inteligência plena. Ensinando e incentivando a aprendizagem e a realização dos alunos. Porto Alegre: Artmed, 2003.

TYLER, L. E. Testes e medidas. Rio de Janeiro: Zahar Editores, 1981.

Texto recebido em 04 de junho de 2011.

Texto aprovado em 19 de novembro de 2012. 